\title{
A representação da ciência e dos cientistas em O Alienista e em outras obras de caráter ficcional
}

\author{
The representation of science and scientists in The Alienist \\ and other works of fiction
}

\author{
ARIADNE CHLOE MARY FURNIVAL \\ Universidade Federal de São Carlos | UFSCar \\ MARCO DONIZETE PAULINO DA SILVA \\ Universidade Federal de São Carlos | UFSCar
}

RESUMO Este artigo estabelece uma rede de convergências discursivas entre a obra O Alienistade Machado de Assis e outros objetos culturais de diversos formatos e suportes por meio da análise hermenêutico-dialética, objetivando demonstrar uma ênfase constante na representação da ciência, por meio da figura do cientista e dos seus elementos circundantes. O trabalho compara estratégias diversas identificadas nessas obras, embasando-se em teóricos preocupados com o papel da ciência e sua imagem. Observou-se, em relação à obra principal, recorrência de uma imagem negativa, impressa por um comportamento excêntrico, antissocial, e autodestrutivo do cientista.

Palavras-chave Ciência na sociedade - imagem do cientista - representações da ciência.

\begin{abstract}
A network of discursive convergences is established between the work The Alienist, by Machado de Assis, and other cultural objects of various forms and physical supports, using a hermeneutic-dialectical framework of analysis, aiming to demonstrate a constant emphasis on the representation of science, through the figure of the scientist and surrounding elements. Strategies identified in these works are compared, with reference to previous works that focused on the historical roles and images of science. Regarding The Alienist, the recurrence of a negative image is observed, conveyed by the protagonist's eccentric, antisocial and self-destructive behaviour.
\end{abstract}

Keywords Science in society - image of scientists - representations of science.

\section{Introdução}

A ciência, como elemento temático de obras conformadas como objetos culturais do gênero ficcional, é o principal assunto de interesse desse artigo, cabendo, no entanto, enfatizar que na presente abordagem, de caráter epistêmico-sociológico, nos propomos a observá-la numa perspectiva do campo da Ciência, Tecnologia e Sociedade (CTS), enquanto espaço de construção social que tanto orientou quanto foi orientado pela ação de seu principal agente: 0 cientista. 
Nosso recorte procurou associar a formulação do tema da ciência e do cientista pela contraposição de trechos pertencentes à obra 0 Alienista ${ }^{1}$, conto escrito em 1882, a obras contemporâneas ao seu autor, Machado de Assis - e a nós mesmos, quando consideradas pertinentes -, e também a obras que considerem tanto o cenário/autor de 0 Alienista quanto o desenvolvimento da ciência (sobretudo da psicologia) enquanto campo científico-institucional.

Nesse interesse, abordaremos, especificamente, o tratamento que é dado em 0 Alienista ao "homem da sciencia" na sua interação com a sociedade dos leigos, e os sentimentos de ambiguidade de ambas as categorias nesse contexto. Demonstraremos que o conto - como outras obras da sua época, e posteriores ao período (trabalhos ficcionais também debruçados sobre o tema da ciência e do cientista) - lançou mão de uma certa imagem do cientista, expressando uma condenação desta imagem pelo extremismo da racionalidade em que a classe científica desembocou. Como ápice desse extremismo, citamos as situações aterrorizantes exemplificadas pelas ocorrências dos campos de extermínio nazistas e pela produção/lançamento das bombas atômicas sobre Hiroshima e Nagasaki, para citar apenas dois exemplos considerados como resultantes da aplicação desse racionalismo radical.

Sendo uma abordagem temático-interpretativa, e tendo como método a análise hermenêutico-dialética, pretendemos analisar os textos sob uma ótica sociológica, observando como se delineiam discursivamente, na literatura, aspectos da ciência e do cientista da sua época, e dos aportes/ecos desses valores na sociedade por nós vivenciada (princípio hermenêutico-dialético essencial para a crítica), trazendo como elementos argumentativos colaboradores: outras obras de caráter ficcional que dialogam com as premissas identificadas em 0 Alienista, por meio de convergências discursivas diretas, ou indiretas; e, documentos literários diversos que estabelecem circunstâncias históricas dos contextos abordados.

Como configurações iniciais sobre o conto, pudemos qualificar a figura do "médico louco" como um recurso quase anedótico - pelo qual o autor critica a racionalidade positivista (escola em ascensão no período). Na condição de ator social, o personagem central - Dr. Bacamarte, um médico - personifica a ciência e serve como instrumento de crítica à noção de que algo científico tem a prerrogativa de ser sempre considerado "bom e racional" ${ }^{\prime 3}$. Sendo seu autor conhecido como admirador e tradutor de Edgar Allan Poe, é bem provável que 0 Alienista tenha sido inspirado no conto do escritor americano The System of Dr. Tarr and Professor Fether, escrito em 1845, já que as duas narrativas tratam de médicos-cientistas que se especializam na loucura e acabam "enlouquecendo" no decorrer da narrativa.

Com a sofisticação e humor típicos dos textos machadianos, 0 Alienista encapsula, no seu tratamento temático do cientista-médico e da ciência, dois motes recorrentes da literatura machadiana: o egoísmo e a vaidade inerentes ao ser humano. A nosso ver, a união dessas duas falhas resulta na concretização dos potenciais perigos para a sociedade: a pregação e aplicação dogmática de uma doutrina orientada por um pensamento acrítico, crente na qualidade indiscutível de suas próprias argumentações.

Assim sendo, iniciaremos nossa discussão num primeiro tópico que pretende apresentar um delineamento sucinto de aspectos relacionados ao cientificismo, que resvalaram na absorção epistemológica da Psicologia como disciplina científica, eminentemente embasada em princípios da Fisiologia e da Biologia, e constituiu-se não só por uma noção de comunidade científica, como por uma necessidade sociopolítica de controle - aspecto desenvolvido no tópico posterior.

\section{O cientificismo e a noção de comunidade: contexto ficcional e realidade}

0 cientificismo, cujas raízes se localizam nas "[...] transformações profundas de mentalidade operadas pela Revolução Científica Moderna (séculos XVI-XVII)." ${ }^{5}$, pode ser definido como uma: "[...] ideologia rendida à obsessividade de crença no progresso linear da vida humana; uma ideologia religiosa da ciência, cultivada com base em crenças dogmáticas e dotada de importantes 'sacerdotes' ". Spinoza são representantes sui generis desse modo de pensar, no qual a fé dogmática se reveste da razão, que é vista como infalível, para tornar-se projeto inquestionável? 
0 cenário mundial pregresso, enquadrado nessa tendência filosófico-científica - de ordem racionalista -, implanta o cuidado sanitarista como um projeto que, no que concerne ao campo da medicina, é reconhecido como originado do pensamento iluminista do século XVIII, e conhecido pela expressão "Saúde dos Povos", numa ordem populacional colonialista, que refletia, então, em termos de poderio político e institucional do campo médico ${ }^{\underline{8}}$. "Desempenhando 0 papel de técnica geral da saúde" diz Jean Luiz Neves Abreu, "[...] a medicina adquire um lugar importante na maquinaria do poder. Os médicos passam a intervir em diversas esferas, estabelecendo topografias sobre a saúde da população, suas formas gerais de existência e de comportamento"

Foi no século XIX, no auge de uma produção prolífica de novas proposições teórico-científicas (tais como o evolucionismo de Darwin, Lamarck e Spencer; a bacteriologia e imunologia lideradas por Pasteur; a economia científica de Smith, Ricardo, Marx e Malthus; o eletromagnetismo de Faraday e Maxwell e a sociologia de Durkheim), em meio a essa avalanche de produção de conhecimentos, reverberando na forma de um "delírio cientificista", uma crença quase cega no: "[...] progresso e na evolução dos conhecimentos que, um dia, explicarão totalmente a realidade e permitirão manipulá-la tecnicamente, sem limites para a ação humana."1ㅡㄴ, ou seja, em meio ao clímax cientificista, quase messiânico, que se escreveu 0 Alienista.

0 conto retrata o trajeto de Simão Bacamarte, um médico que retorna ao Brasil depois de conquistar prestígio em Portugal e, atraído pelos estudos da ciência, investe no aprofundamento dos conhecimentos e práticas da medicina quando, então: "[...] que um dos recantos desta lhe chamou especialmente a atenção -o recanto psíquico, o exame de patologia cerebral." "11 Daí em diante, obcecado por esse interesse em salvaguardar a "saúde da alma" por meios científicos, as ações de Bacamarte produzem graves intervenções no campo social e político de Itaguaí, vila onde vivia o médico e sua esposa, D. Evarista.

Esse mote inicial servirá para observarmos duas características essenciais ao cientificismo da época em que se localiza o conto e que, a nosso ver, repercutem as críticas da narrativa: a primeira pela ideia de que todo mal psicológico tem uma origem física ou orgânica; e, a segunda pela defesa de que a "salvação" do indivíduo por uma saúde da alma poderia ser um projeto executável a partir de um interesse, a princípio, aparentemente altruísta, mas tornado completamente desumano no desenvolver da estória. Ambas qualificações redutoras do que seria e de "onde" viria a loucura, assim como uma "razão" altruísta para alienação de seus "portadores".

0 positivismo, como a versão mais agressiva do caráter cientificista, difundido no Brasil desde 1840른 representa tanto a expressão política dessa postura (a ideia de higienização social) quanto uma base teórica materialista (o fisicalismo e 0 organicismo). 0 positivismo é: "[...] a fórmula filosófica que permite transmutar a ciência em religião."프, uma religião, desprovida, no entanto, de tons teológicos ou metafísicos, uma crença que repousa estritamente no "fato observado". Em resumo: "[...] a atitude positivista é caracterizada, quanto ao método, pela subordinação da imaginação à observação."14, observando-se mais adiante que, no positivismo: "Os fatos são valorizados pelas suas características exteriores."

No tocante a noção de comunidade científica, consideramos que o desenvolvimento da psicologia se deu pela aliança desta à onda positivista do século XIX, sobretudo pela necessidade de reconhecimento de sua cientificidade. A psicologia, oriunda de um ramo da filosofia - conhecido, então, como antropologia filosófica -, buscou amparo na ordem das ciências experimentais (sobretudo biológicas ou fisiológicas) que reduzia: "[...] os fenômenos psíquicos aos fenômenos orgânicos e cerebrais [...] 0 homem passou a ser estudado em laboratórios [...] e a psicologia enveredou-se pelos caminhos traçados pelo organicismo e pelo mecanicismo clássicos. "16

0 tom de crítica ao projeto desse cientificismo, no campo da psicologia, é por nós atribuído à narrativa de 0 Alienista por entendermos que, desde 0 início, o conto faz com que o leitor desconfie da eficácia dos métodos e da própria competência científica do protagonista da trama. No entanto, não o faz sem intensificar o processo de debate filosófico - ainda que absurdo - que o racionalismo exacerbado de Bacamarte promove, tornando o personagem excêntrica e obsessivamente dominado pela necessidade de solução dos enigmas com que se depara na observação do comportamento da população que aprisiona. 
Note-se que a metodologia de Bacamarte reside, sobretudo, no processo de observação e registro dos comportamentos, visando identificar traços de "desvio" nos indivíduos e alienação (com finalidade saneamento social) do mesmo na Casa Verde, hospício criado pelo próprio Bacamarte. Esse caráter ostensivo e sanitarista do médico acaba por torná-lo emocional e humanamente inepto e prefigura, na proposição desse trabalho, como perfil consagrado ao cientista, tanto no contexto histórico do conto quanto no nosso, com trabalhos ficcionais na mesma temática e de mesma envergadura.

A alienação é descrita como um elemento de controle social em que, no início de sua implantação tem o hospício como: "[...] uma tecnologia voltada para a disciplinarização e moralização da cidade, e não apenas uma forma medicalizada de exclusão social [...]"플 , ou seja, 0 ato de trancafiar os elementos tidos como "loucos" atenderia ao mesmo tempo um desejo de saneamento "civilizatório" e "anímico" - evolução tanto no plano coletivo quanto individual. Esse caráter de disciplinarização é enfatizado em outro texto em que se conjuga à função de "limpar" a cidade, a de: "[...] garantir a ordem e de difundir preceitos ou padrões de comportamento." 18

Em contrapartida, ao se apresentar um levantamento dos tipos que viviam em meados do século XIX nas ruas do Rio de Janeiro, observa-se que tais indivíduos, apesar: "[...] das perseguições, das vaias, dos risos, das chacotas e das agressões físicas [...] eram também objeto de compaixão, simpatia e consideração; alguns [...] chegaram mesmo a ser profundamente estimados, respeitados e até admirados." $\underline{19}$

Essa circunstância, a nosso ver, favorece nossa interpretação de que o autor do conto simpatiza com a ordem libertária desse contexto carioca, provocando um sentimento de crítica pela onda alienista que, com o advento do pensamento positivista, ganhava força no país.

Ainda se observa que, em termos legais, o reconhecimento e aprisionamento de indivíduos considerados loucos era uma prática regulada pelas leis do império que exigiam alienação, ou salvaguarda do indivíduo se o mesmo apresentasse sinais de loucura, ou de possibilidade de causar danos a si mesmo ou a outrem:

[...] o exame médico de sanidade passaria a ser exigido nesses casos a partir de um acórdão da Relação do Rio de Janeiro, promulgado em 22 de julho de 1851, pouco menos de um ano antes da inauguração do Hospício de Pedro II - primeira instituição brasileira especialmente destinada a alienados - que, como se verá, representaria importante etapa da luta pela medicalização da loucura, encaminhada por médicos brasileiros a partir dos anos 30 do século XIX.믄

Uma das etapas intermediárias dessa "medicalização da loucura" foi a promulgação do Código Civil Brasileiro, ocorrido em 1916, pelo qual se qualifica o especialista (alienista) como um dos elementos capacitados - dentre os legistas e juristas - a identificar e avaliar graus de anormalidade:

Conforme avaliação dos especialistas, a amplitude dos estados intermediários da capacidade mental justificaria a necessidade de medidas legais também intermediárias. [...] os psiquiatras e legistas consultados por Camargo defendem a interdição parcial. Mas enquanto a inflexibilidade da lei persistisse, o perito não deveria hesitar, optando, segundo o Dr. Humberto Gottuzzo, "pela solução que melhor defenda a pessoa e os bens do anormal", já que seria preferível submetê-lo ao cerceamento absoluto dos seus direitos civis - ainda que reconhecidamente excessivo em muitos casos - do que fugir da missão quase sagrada de defendê-los de seus próprios atos. $\underline{\underline{21}}$

Dessa valorização do conhecimento médico numa esfera político-social, apresentada anteriormente ${ }^{22}$, até essa consideração em torno da qualificação do psiquiatra como profissional capacitado a opinar de maneira conclusiva sobre o estado de normalidade, ou anormalidade, entendemos que o projeto de alienação, como tecnologia $a^{23}$, foi um ferramental pelo qual a comunidade científica da área, na situação de desenvolvimento da psiquiatria, sedimentou sua busca de reconhecimento e valorização.

Por essa via, o conto situa seu leitor em um contexto histórico em que Bacamarte é, então, reconhecido, nas linhas de abertura da obra, como evocação desse espírito cientificista, informando-se, no desenvolvimento dessa introdução, 
que o personagem-cientista se incumbiu da missão de descobrir, em Itaguaí, uma cura universal da loucura, acreditando contribuir, verdadeira e cientificamente, com o progresso humano e civilizacional, estudando e classificando a loucura em "seus mais diversos graus" $\underline{24}$. Em suma, tanto se enfatiza a índole humanitária e altruísta do personagem cientista quanto se desdenha da capacidade e eficiência que essa ciência arroga a si mesma.

Ao se versar sobre a figura e papel do cientista na sociedade, enumeram-se os papéis do cientista como perito, como trabalhador técnico e como um entrepreneur intelectual 25 . Simão Bacamarte se enquadra, a nosso ver, na descrição desta última categoria, caracterizando-se como alguém que age segundo: "[...] sua própria iniciativa com base numa avaliação pessoal da probabilidade de fazer uma descoberta, e ser premiado com reconhecimento pessoal se for bem-sucedido. As feições da personalidade apropriadas a este papel são: a curiosidade [...] inteligência [...] persistência [...] honestidade [...]."트

Apesar da sua dimensão individualista - persistente em Bacamarte -, considera-se que: "[...] a ciência acadêmica não é anárquica."그 e, por essa ótica, o cientista faria, idealisticamente, parte da "República da Ciência" - conceito que associamos à expressão "República das Letras", uma comunidade virtual, existente no século XVI-XVII, que irmanava os intelectuais do período por meio de uma identidade coletiva, mutuamente compartilhada ${ }^{28}$. No contexto apontado $\underline{29}$, essa ideia expressava uma coletivização das atividades científicas, um território simbólico que se autogovernava por meio do que hoje se denominaria"normas mertonianas", preconizando condutas orientadas por valores sagrados - espírito crítico, desinteresse, comunalismo e universalismo..$^{30}$

No entanto, conforme as representações ficcionais da ciência por nós analisadas, há o elemento ameaçador do isolamento do cientista, derivando uma ciência desenvolvida às margens (e até, em detrimento) da sociedade, que toma uma dimensão dramática associada à imagem do cientista na sua busca por conhecimento "de ponta" - busca qualificada, usualmente, como sigilosa, ou, na melhor das hipóteses, imune ao controle da comunidade de pares científicos ${ }^{31}$. Esse isolamento, aliado ao desejo de reconhecimento, geralmente de base narcisista, fazem o personagem cientista perder, tragicamente, a perspectiva real dos impactos de seu trabalho, violando os princípios éticos por uma busca obsessiva por uma verdade "individualista", ou, até mesmo, por interesses menos relacionados ao bem estar coletivo que ao de grupos privados ou ideologias fascistas.

No conto 0 Alienista, a comunidade científica mais ampla é representada por uma coletivização de ideia de ciência, sem, no entanto, corporificar esta ideia num grupo científico presente espacialmente. Enfatiza-se tal situação pelo artifício de ausência de nomes de outros cientistas, em Itaguaí, relacionados ao campo científico: embora o alienista seja imbuído na cultura cientificista do seu tempo, as referências feitas à comunidade científica são generalizadas, quando não, escassas. Com efeito, a única alusão en passant que o alienista faz aos seus pares profissionais é no momento de conflito com um grupo de cidadãos revoltantes ("os Canjicas") liderados pelo barbeiro, Porfírio, que - numa cena semelhante àquelas dos filmes de Frankenstein, na qual uma multidão da aldeia marcha até residência do cientista-vilão da trama - com o objetivo de pôr fim aos seus exageros, conclama o fechamento do asilo da Casa Verde e o fim das experiências do alienista. Bacamarte, por sua vez, trata os cidadãos com nítido menosprezo e arrogância, respondendo à exigência coletiva:

\begin{abstract}
Meus senhores, a ciência é coisa séria, e merece ser tratada com seriedade. Não dou razão dos meus atos de alienista a ninguém, salvo aos mestres e a Deus. Se quereis emendar a administração da Casa Verde, estou pronto a ouvir-vos; mas, se exigis que me negue a mim mesmo, não ganhareis nada. Poderia convidar alguns de vós em comissão dos outros a vir ver comigo os loucos reclusos; mas não o faço, porque seria dar-vos razão do meu sistema, o que não farei a leigos nem a rebeldes. $\stackrel{32}{.}$
\end{abstract}

Esta referência passageira aos "mestres", de certo modo subordinada numa hierarquia de autoridade (com Deus no topo), reforça a imagem arrogante do cientista, imune às demandas sociais. Diante deste discurso preciso do alienista, os rebeldes ficam "atônitos", não sendo coincidência que o barbeiro, oportunamente, identifique essa sensação de incapacidade e impotência política por parte do povo como sendo o "[...] momento decisivo que [...] sentiu despontar em si a ambição do governo [...]" ${ }^{\prime \prime}$, configurando-se como mais um instante carregado de ironia e cinismo machadiano. 
Dessa forma, a comunidade científica fica, alegoricamente, restrita à figura de Bacamarte - e, nessa circunstância, também a ideia de governabilidade. Bacamarte delibera, ele mesmo, sobre a assertividade de seus atos, sem que uma noção mais coletiva de princípios seja compartilhada, ou seja, consubstancia-se como uma administração "autocrática" do fazer científico, determinada pela concepção única e autônoma de uma só perspectiva. Em termos de estabelecimento de relações entre essa atitude do cientista e "aceitação" da instituição ciência(Psicologia) ${ }^{34}$, conjugam-se pela constituição do campo em construção num fazer científico orientado pela observação comportamental dos indivíduos, tentando conciliar as "anormalidades" a questões orgânicas ou hereditárias.

Notamos acentuada a negatividade com que o conto enxerga a onda positivista no Brasil, pois:

[...] o movimento dos enunciados do Dr. Simão Bacamarte permite perceber o significativo ceticismo do escritor brasileiro diante de um mundo que se despede e outro que chega enraizado no primado iluminista da razão: basta notar que, em O alienista, se descreve um país colonial em seus hábitos, no qual se introduz, todavia, a novidade do mundo moderno da ciência, cuja função, depreendida do papel do protagonista, seria a modernização e a civilização dos hábitos sociais. $\frac{35}{5}$

É curioso observar a descrição do que se tinha por psicologia na época do conto: “Julgo applicavel à psychologia o que disse da economia politica um jurista francez: ella não é uma sciencia, mas apenas um estudo; e eu accrescentaria: - um entretenimento. "트. Ou, quando se tece uma descrição de plantas inculcando nos elementos observados uma qualidade psicológica específicamente botânica ${ }^{37}$. Ou, ainda, a crítica irônica ao positivismo como solução ao problema econômico:

Os ricos serão então obedecidos sem inveja e venerados como os depositarios de um capital que não póde ser conservado e desenvolvido para o bem commum sem a concentração e a apropriação pessoal. E os pobres terão no salario, nâo a paga de um serviço, porém os meios gratuitamente fornecidos a cada um pela humanidade, para o desempenho de deveres que são a fonte perenne da felicidade. $\frac{38}{n}$

Nota-se nesses ensaios tanto uma resistência em aceitar a Psicologia como um regime científico sério quanto a tentativa de manter seu lastro de disciplina biologicamente enraizada, cabendo ainda uma crítica ao pensamento e filosofia positivista - ainda que na ordem da divisão do trabalho. Tais admoestações mostram que o pensamento contrário aos moldes do que se entendia por ciência também se manifestava em outras formas de literatura, além da ficção, tipologia pela qual se orienta 0 Alienista.

\section{Bacamarte, o cientista, o meio social e a perspectiva pública da ciência}

A composição de Simão Bacamarte em 0 Alienista remete a uma longa tradição ficcional de representação do cientista como uma figura obcecada por sua vocação, um indivíduo potencialmente perigoso para a sociedade. Nessa típica representação ficcional (presente tanto em romances góticos dos séculos XVIII e XIX quanto em filmes, romances e revistas em quadrinhos contemporâneos) é raro se ver cientistas representados como heróis, sendo mais comum vê-los ocupando o perfil de homens ambiciosos, desumanos, insensíveis e excentricamente orientados. $\frac{39}{9}$

Essa excentricidade,representada geralmente pela articulação de uma atitude "deslocamento" do cientista em relação ao seu habitat, sendo seu papel de pesquisador exercido "distanciadamente", às margens da comunidade a que pertence (em castelos, ou casas grandes e imponentes, construções afastadas do centro da cidade) - admitindo-lhe a manutenção de uma relação meramente observatória e experimental -, circunstância que, no caso de Simão Bacamarte, tem como espaço de projeção o asilo Casa Verde, com consequentes impactos no cotidiano de seu ao redor: Itaguaí. 
0 recurso de distanciar espacialmente o personagem cientista de seu meio proporciona, também, a ênfase em um aspecto essencial ao ideal positivista: o mito da imparcialidade científica. A possibilidade do olhar "distanciado", no conto, é entendida como necessariamente objetiva, simbolizando, inclusive, uma exigência científica, dada a ameaça social que um trabalho "dessa envergadura", potencialmente, implicaria para a sociedade "despreparada". Em contraponto, essa separação de territórios também aponta para o exercício de uma ciência "não controlada", como na história do Dr. Frankenstein (escrito em 1818)ํㅡ, um exemplo emblemático dessa crítica à fé cega no cientificismo. ${ }^{41}$

Também se afirma que a representação do cientista na literatura ocidental como indivíduos bons, desde os tempos medievais até o presente, é minoria, reconhecendo categorias recorrentes nesse processo de estereotipagem². Fazendo uso dessa classificação para estabelecer um perfil à Simão Bacamarte, reconhecemo-lo numa classe que se consolida a partir de sua impotência diante da "ciência", o conduzindo à perda de sanidade ou, ainda, pela perda de humanidade, incorporando o estereótipo mais duradouro e de maior recorrência, surgido durante o romantismo europeu como reação ao materialismo científico do iluminismo.

A feição desumana de Bacamarte se exterioriza por meio de ações inescrupulosas para com os sujeitos da sua pesquisa, suprimindo suas emoções e noções éticas (e morais) em detrimento de seus objetivos "científicos" e valores filosóficos racionalistas. É apresentada, também, uma lista de fatores que contribuem para a desumanização $0^{43}$, dos quais podemos identificar, no personagem de 0 Alienista, a descrição da ação correspondente a um deles (repressão de sentimentos humanitários), apresentado em destaque no seguinte trecho:

Conquanto as lágrimas de D. Evarista fossem abundantes e sinceras, não chegaram a abalá-lo. Homem de ciência, e só de ciência, nada o consternava fora da ciência; e se alguma coisa o preocupava naquela ocasião, se ele deixava correr pela multidão um olhar inquieto e policial, não era outra coisa mais do que a ideia de que algum demente podia achar-se ali misturado com a gente de juízo. $\underline{\underline{4}}$

Paradoxalmente, o interesse que Bacamarte demonstra diante dos detalhes minuciosos da vida rotineira dos sujeitos do seu experimento científico via observação comportamental, não encontra reflexo na sua própria vida pessoal, que fica totalmente negligenciada devido à sua dedicação exclusiva à ciência, como ilustrado neste trecho:

Isto feito, começou um estudo aturado e contínuo; analisava os hábitos de cada louco, as horas de acesso, as aversões, as simpatias, as palavras, os gestos, as tendências; inquiria da vida dos enfermos, profissão, costumes, circunstâncias da revelação mórbida, acidentes da infância e da mocidade, doenças de outra espécie, antecedentes na família, uma devassa, enfim, como a não faria o mais atilado corregedor [...] Ao mesmo tempo estudava o melhor regímen, as substâncias medicamentosas, os meios curativos e os meios paliativos [...] Mal dormia e mal comia; e, ainda comendo, era como se trabalhasse, porque ora interrogava um texto antigo, ora ruminava uma questão, e ia muitas vezes de um cabo a outro do jantar sem dizer uma só palavra a D. Evarista. $\frac{45}{5}$

Ao mesmo tempo em que, nas representações ficcionais, o cientista trabalha obsessivamente às margens da sociedade, impedindo-lhe de estabelecer laços com o mundo real e/ou emocional, seu trabalho começa a afetar, também, a vida pacata dos cidadãos comuns - as histórias de Frankensteinn" de A Ilha de Dr. Moreau (de 1896) ${ }^{47}$, e Dr. Jekyll e Mr. Hyde (192-?)ํ, são modelares, nesse sentido. A privacidade e isolamento, características da rotina do cientista, contrastam com a forma pela qual as repercussões do seu trabalho, literalmente, invadem ou constrangem o espaço privado dos cidadãos.

No caso de 0 Alienista, Bacamarte assume uma postura de "todo-poderoso", capaz de confinar na Casa Verde, aleatoriamente, ou não, qualquer cidadão que, segundo seu julgamento, careça de juízo, tendo o aval sócio político que utiliza ora do status do especialista (inacessível para compreensão de leigos), ora do terror com que a autoridade científica delibera seus valores, conforme salientado a seguir: 
Acumulando a Câmara as suas tarefas jurídico-administrativas e o poder de executar, a vereança favorece o império do mando. Nem é outro o regime que vigora na vila de Itaguaí. A rigor, trata-se do poder de médico versus a fraca resistência do leigo, com os vereadores de caráter vacilante e ideias inconsistentes de permeio. $\underline{49}$

Um paralelo interessante sobre esse tipo de negociata, a busca de conciliação entre os desejos de salvação do corpo - noção higienista - e da alma - noção messiânica - é apresentada quando se descreve o processo de "endeusamento" do judiciário na caça e penalização de nomes políticos circulantes na grande mídia brasileira ${ }^{50}$. Um fator populista que advoga a partir de uma pseudoneutralidade que visa uma pseudojustiça, orientada para a estabilização de um status quo compactuado: "ordem e progresso" a todo e qualquer custo. Salientando-se a ironia do lema positivista como reaquisição do governo brasileiro no pós impeachment de 2016.

Em Brave New World (1946) ${ }^{51}$, Aldous Huxley descrevia como os avanços tecnocientíficos suscitaram uma sociedade ameaçadora na qual se perdera o direito de um espaço privado para o indivíduo ${ }^{\underline{52}}$. 0 Alienista, muitos anos antes, e de modo bem menos sombrio, mostra como Bacamarte, cientista omnisciente - detentor do poder de decisão sobre a vida dos cidadãos - viola a privacidade de alguns cidadãos de Itaguaí, internando-os no manicômio, baseando-se na ruptura de convenções, conforme a descrição que faz do elementos que determinaram sua decisão de trancafiar a própria esposa:

[...] esta noite, porém, declarou-se a total demência. Tinha escolhido, preparado, enfeitado o vestuário que levaria ao baile da Câmara Municipal; só hesitava entre um colar de granada e outro de safira. Anteontem perguntou-me qual deles levaria; respondi-lhe que um ou outro lhe ficava bem. Ontem repetiu a pergunta ao almoço; pouco depois de jantar fui achá-la calada e pensativa.-Que tem? perguntei-Ihe.—Queria levar o colar de granada, mas acho o de safira tão bonito!-Pois leve o de safira.-Ah! mas onde fica o de granada?-Enfim, passou a tarde sem novidade. Ceamos, e deitamo-nos. Alta noite, seria hora e meia, acordo e não a vejo; levanto-me, vou ao quarto de vestir, acho-a diante dos dois colares, ensaiando-os ao espelho, ora um ora outro. Era evidente a demência: recolhi-a logo. $\underline{53}$

Elementos circunstanciais são tidos como prova cabal de desequilíbrio, como quando Bacamarte, acompanhado do seu colega Crispim Soares, o boticário, espia Mateus, um artesão que desejava ser admirado pelos cidadãos de Itaguaí por ter se enriquecido, desejo esse tomado pelo alienista como uma clara evidência de loucura. Em suma, o padrão que se repete é o do alienista observando "cientificamente" comportamentos e costumes sociais considerados normais para a época e o contexto, mas que do ponto de vista excêntrico e socialmente marginalizado do personagem, aparentam ser sinais de debilidade mental expressa por uma desordem comportamental observada sistemática e depreciativamente.

No conto, por meio desse mecanismo de sistematização extrema do pensamento de Bacamarte, confere-se à ação científica de julgar e rotular uma qualidade de extremo ridículo, incidindo, no entanto, uma crítica contundente aos valores e convenções da sociedade observada por Bacamarte, deixando claro que o médico pratica uma ciência "descontrolada".

A ameaça que este descontrole representa encontra seu reflexo na delineação da figura do cientista como psicologicamente instável, e socialmente irresponsável, sendo a ciência também aviltada nesse processo. Não é por acaso que o capítulo no qual são narrados os casos de internação de grande parte da população da cidade seja intitulado "0 Terror" que faz alusão ao pânico social terrorista que se instala em Itaguaí, sobretudo pelo peso social e político com que se revestem as decisões do médico, atmosfera semelhante, a nosso ver, e com as devidas proporções, ao estado de convulsão social em plena Revolução Francesa ou ao caos nazi-fascista implantado na Alemanha e na Itália durante as décadas de 1930-1940.

Tem sido bem documentada na literatura científica a "compreensão e percepção pública da ciência", como quando, frequentemente,os cidadãos leigos manifestam simultaneamente: “[...] atitudes misturadas de reverência e reserva, 
aprovação e inquietude, entusiasmo e antipatia." ${ }^{\prime 54}$ a respeito de assuntos científicos. Devido à não-homogeneidade de contextos científicos e tecnológicos, não se considera fora de propósitoencontrar, até os dias de hoje, um público - seja leigo ou especialista - com sentimentos e entendimentos sobre e da ciência, ou da tecnologia, à primeira vista contraditórios.

Em termos de especialização, observa-se que mesmo na contemporaneidade resistem indícios de um pensamento positivista em áreas como as da psiquiatria - sobretudo pela obsessão classificatória -, conforme expresso a seguir: "[...] a partir da terceira versão do Manual diagnóstico e estatístico de transtornos mentais (DSM-III), publicado em 1980 - [que] pretende ser fundamentalmente "a-teórica", "descritiva" e isenta de discussões etiológicas." $\underline{55}$.

Em termos de senso comum, as contradições de entendimento podem decorrer da forma como a ciência e a tecnologia são interpretadas: servidoras da indústria (ou de um poder político-econômico) e um conjunto de conhecimentos imparciais e neutros; fonte principal de riscos e danos ambientais e base mais racional para a avaliação de riscos ao meio; tema irrelevante na luta do dia-a-dia e melhor caminho para o "progresso" social..$\underline{6}$

A percepção dessa ambiguidade, em pleno século XVIII, foi muito bem representada pela área da pintura, na obra Uma Experiência com um Pássaro numa Bomba de Ar, exibida em 1768. 0 quadro ${ }^{57}$ mostra um cientista demonstrando a formação de um vácuo para um grupo de mulheres, homens e crianças, cada um destes espectadores evidenciando expressões de reações distintas ao experimento, desde perturbação e aflição, até indiferença ou desinteresse.

Pode-se observar na pintura que um pássaro branco, numa das câmaras de vidro da bomba, está evidentemente perecendo na medida em que 0 cientista retira 0 ar da câmara. Por isso, uma das crianças cobre o rosto e está claramente perturbada com o resultado, sendo confortada por um homem, que, apontando à câmara, parece estar insistindo na exigência de sacrifício da ave pela necessidade de explicação do princípio científico em pauta. A noção vencedora desse dilema parece ser que a explicação racional, e o ganho pela demonstração empírica, devessem consolar a menina.

Outro espectador, muito pensativamente, parece ponderar as implicações do experimento, enquanto mais outro comunica, por meio da sua postura reta e atenta, um engajamento e interesse agudos na defesa da ciência, como se estivesse testemunhando algo de grande teor sagrado. Um casal entre os espectadores parece estar indiferente à experiência, mais absorvido no jogo amoroso entre si. Há, ainda, uma luz intensa no centro da cena, iluminando 0 momento de revelação da verdade científica. No entanto, esta luz parece emanar de uma jarra contendo uma caveira suspensa em líquido, posicionada na frente da mesa, aludindo, simbolicamente, a uma possível relação entre a morte - sacrifícios -, conhecimento e avanços científicos.

0 cientista retratado na pintura - um tipo evidentemente excêntrico, com seus cabelos longos e grisalhos, sua roupa não-convencional - lança, de forma desafiante, seu olhar para fora da cena, fitando-nos diretamente, os observadores do quadro. Esse recurso parece nos envolver, impondo-nos que, como espectadores, decidamos se o resultado do experimento é moralmente aceitável, ou não. Este dilema é reforçado pelo estado transitório da ave, entre a vida e morte, à mercê de nossa intervenção. Ainda que olhar do cientista nos "aprisione" na expectativa dessa decisão, contraditoriamente, expressa sua indiferença à opinião alheia e, sobretudo em relação às reações das outras personagens no quadro. Em resumo, essa pintura ilustra bem: "[...] a maravilha e o horror da ciência como foi conhecida no século XVIII. $\underline{50}$, uma área interventora, mas pouco afeiçoada à crítica e controle públicos.

Na perspectiva deste artigo, essa ambiguidade experimentada pelas pessoas diante da ciência é também representada em 0 Alienista, pois, ao mesmo tempo em que a cidade de Itaguaí - o Brasil - está imbuída pelo espírito da mitificação da razão (que alimentou o cientificismo da época), seus cidadãos expõem, desde a abertura do conto, sentimentos ambivalentes em relação a ela, sobretudo pelos questionamentos em torno da sanidade de Simão Bacamarte.

0 aumento de desconfiança na sanidade do alienista (e por extensão, no conhecimento científico) é proporcional ao crescente número de internações de cidadãos que este encaminha ao manicômio, resultando na confrontação entre os protestos de uma população "revoltada" e a segura argumentação de Bacamarte, em que este último, arrogantemente, desqualifica seus opositores em relação à racionalidade científica, justificando sua conduta pela consideração de que: "[...] a ciência era a ciência, e que ele não podia deixar na rua um mentecapto." $\underline{59}$ À falta de uma liderança à 
altura do poder retórico do cientista, o percebido exagero das ações do alienista passaria, então, a ser explicado, na visão dos itaguaenses, apenas por alternativas igualmente exageradas, beirando a instalação de um surto paranoico coletivo (latente), expressa pela qualificação de tais de atos como "vingança, cobiça de dinheiro, castigo de Deus, monomania do próprio médico, plano secreto do Rio de Janeiro com o fim de destruir em Itaguaí qualquer gérmen de prosperidade que viesse a brotar, arvorecer, florir, com desdouro e míngua daquela cidade, mil outras explicações, que não explicavam nada, tal era o produto diário da imaginação pública."트

A população, em consequência desse contexto tenebroso, destitui qualquer possibilidade de benefícios científicos, relegando a ciência a um plano secundário em relação às suas superstições e ao senso comum: "A verdade científica é sempre um paradoxo, se julgada pela experiência cotidiana, que apenas agarra a aparência efêmera das coisas."

Se a esfera "pública" populacional adota, em geral, uma postura ambivalente e cética em relação à ciência do alienista, os cidadãos da elite política são, na maior parte, aliados submissos do poder "incontestável" do cientista autoritário, pois, mesmo após tentativa de "revolução" pelos Canjicas, liderados pelo barbeiro Porfírio - iniciada com 0 único objetivo de por fim à Casa Verde e aos experimentos do alienista -, a estabilidade é rapidamente reinstaurada, com o próprio Porfírio negociando uma aliança pacata com Bacamarte, alegando, em conversa com o cientista que:

Com razão ou sem ela, a opinião crê que a maior parte dos doidos ali metidos estão em seu perfeito juízo, mas o governo reconhece que a questão é puramente científica e não cogita em resolver com posturas as questões científicas. [Finalizando que] A generosa revolução que ontem derrubou uma Câmara vilipendiada e corrupta, pediu em altos brados o arrasamento da Casa Verde; mas pode entrar no animo do governo eliminar a loucura? Não. E se o governo não a pode eliminar, está ao menos apto para discriminá-la, reconhecê-la? Também não; é matéria de ciência. Logo, em assunto tão melindroso, o governo não pode, não quer dispensar o concurso de Vossa Senhoria. $\underline{62}$

0 conto 0 Alienista contém: “[...] vinhetas extraordinárias da fauna política do Brasil."트 A loucura como tema da obra aqui analisada simboliza, até certo grau, uma "loucura" subjacente ao cenário político local, mas, não necessariamente, isolado de um caráter mais universal, pois pode se reconhecer no desenvolvimento desse plot temático, um discurso condescendente e/ou oportunista da classe dirigente. Observa-se, nesse tocante, que mesmo deflagrada a rebelião, rapidamente se instala um novo governo, indistinguível do anterior, razão pela qual se entende que o que se prioriza, em política, é um estado de equilíbrio relativo entre as forças do poder - em situações de crise - como um elemento estrutural.

0 escritor da obra acreditava que a falta de interesse na política era típica da sua geração e que essa se devia muito a um estado de estagnação preponderante, assinalando-se ainda que, na concepção do escritor, o termo "Política" não se referia apenas à conciliação entre dois partidos políticos, mas sobretudo: "[...] um abrandamento conveniente de políticas diversas dentro da oligarquia dominante [...] pura acomodação cínica." ${ }^{64}$ Na situação abordada em 0 Alienista, o fato político mais significativo, a rebelião liderada por Porfírio, resulta, simplesmente, em maior "paralisia" do sistema político, ou seja, absorção da crise na forma de uma "catatonia" social.

De fato, 0 Alienista mereceria uma análise exclusiva do seu tratamento temático sobre a política, entretanto, uma vez que esse não foi o enfoque pretendido por nós no presente trabalho, consideramos, então, que nos basta salientar que, como vários outros protagonistas machadianos que apenas pensam na sua própria ascendência social, as autoridades políticas de Itaguaí - sejam elas antes ou depois da posse de Porfírio (com a curta duração de duas horas no posto) no governo de Itaguaí - veem na ciência um aliado ou inimigo, conforme a situação lhes parece favorável ou desfavorável.

Em termos científicos, a afirmação desse viés político ressoa como percepção da preconização de certo ethos que 0 Alienista, por meio do seu estilo satírico, endereçara contra o positivismo, um sistema: "[...] bastante em voga entre a elite intelectual brasileira... [sátira que] tornou-se muito menos específica no sentido filosófico, evoluindo para a condenação de qualquer doutrina [...] que justificasse o egoísmo e o egocentrismo." $\underline{65}$, sendo teoricamente defendido como manutenção de uma ordem "natural", mas praticamente refutada, ao longo do tempo, pela ordem "social" dominante. 
Por fim, consideramos comum que a inépcia social do protagonista cientista, nas representações ficcionais, seja compensada pelas "competências sociais" $\underline{66}$, geralmente atribuídas às figuras femininas coadjuvantes (usualmente a esposa, a filha, ou a assistente de laboratório) - tal como no filme $A$ vida de Louis Pasteur ${ }^{67}$, no qual, Marie, a esposa de Pasteur, é o estereótipo (ou protótipo almejado pelo sistema acadêmico?) de uma mulher inteiramente submissa ao marido e, indiscutivelmente, identificada com o papel feminino de guardiã do lar - espaço no qual todo cientista encontra refúgio e apoio. Também se nota no filme momentos nos quais um modelo de ação feminina, dirigida social e emocionalmente, provê alívio ao caráter obsessivo, nervoso, e até autoritário, de Pasteur.

Identificamos nas proposições acima ${ }^{\underline{60}}$, a atribuição de uma função de "mediação social" à qualidade feminina, função que, a nosso ver, D. Evarista, voltando de sua estadia no Rio de Janeiro, vem a ocupar em outro momento de 0 Alienista. Neste momento a população a enaltece, conferindo-lhe uma fé legítima de "esperança de Itaguaí", pois: "[...] contava-se com ela para minorar o flagelo da Casa Verde. Daí as aclamações públicas, a imensa gente que atuIhava as ruas, as flâmulas, as flores e damascos às janelas." $\underline{69}$ No entanto, mais uma vez com muita ironia e humor, demonstra-se que a fé, agora depositada em D. Evarista, havia sido calculada equivocadamente, uma vez que sua vaidade, pretensões de destaque e postura submissa ao marido, constituintes do comportamento feminino ditado pelos costumes da classe e época, adicionados à fragilidade de "caráter" de D. Evarista, impõem que ela se curve facilmente, minando qualquer esperança redentora.

Relata-se a condição de isolamento das mulheres no hospício do Juquery $\underline{70}$, as dificuldades, por exemplo, de manutenção de liberdade no caso de uma mulher de classe alta apresentar um "desvio" de conduta das convenções sociais, sobretudo se tais "desvios" ofendessem a ordem patriarcal:

A psiquiatria brasileira - ela mesma senhorial e misógina - desempenhou aí perfeitamente seu papel de instrumento desta cultura senhorial e masculina [...] Percorrendo milhares de prontuários psiquiátricos do hospício do Juquery entre 1895 e 1930 [...] nunca vi um único caso de mulher que tenha conseguido ser ouvida e fazer valer seus direitos em face do poder discricionário dos pais e maridos aliados ao psiquiatra. $\underline{71}$

Em suma, nesse sentido, D. Evarista estava fadada a clausura no Casa Verde, uma vez que, além de marido, Bacamarte era também o psiquiatra que Ihe julgaria a conduta. Assim, D. Evarista é representada como uma figura patética, fracassada em relação aos padrões patriarcais de feminilidade-maternidade da sua época (por não ter conseguido produzir um herdeiro para o marido), passando a incorporar o comportamento frívolo e consumista atribuído a mulheres da sua classe, um perfil em cujas demonstrações de sentimentalidade e pieguice têm a função dramática de realçar a frieza e incapacidade emocional do marido cientista, ao mesmo tempo que explicitam sua qualidade trágica.

\section{Conclusão}

Esperamos ter demonstrado neste trabalho como, por meio do conto 0 Alienista, estão sintonizados alguns objetos de ordem ficcional mundial no tratamento de temas como os de ciência e do cientista, mais especificamente, quando relacionados com a perda de controle do fazer científico pelo caráter excêntrico do cientista em níveis de comunidade institucional e instrumentalidade da psiquiatria no controle social.

0 cientista de 0 Alienista, como muitos outros cientistas ficcionais, de variados suportes e formatos, é um homem que trabalha, obsessivamente, às margens do mundo que, desesperadamente, quer "conquistar", tendo por meioa comprovação de suas teorias. Bacamarte poderia estar trabalhando em qualquer país e contexto social, ainda que 0 vislumbremos em 0 Alienista, na atmosfera de uma ordem nacional e provinciana.

Salientamos, particularmente, o investimento das inscrições críticas e satíricas do autor no tocante à estagnação do sistema político, e ao consequente vácuo por ela gerado que, por sua vez, é rapidamente preenchido pela ciência. 
Os cidadãos e os políticos de Itaguaí apoiam o trabalho que eles mesmos reconhecem, nos seus momentos de intuição sensata, como sinal do "desequilíbrio" de Bacamarte, justamente porque o idealismo com o qual este apresenta o seu experimento Ihes permite vislumbrar: "[...] ordem, racionalidade e assim, otimismo em um universo que apareceu como arbitrário e caótico."끄 Ou seja, a busca de alguma resposta "salvadora" justifica o risco pressentido.

Essa "salvação" pela ciência, ecoa, ainda hoje, nas promessas de um preceito central à sociedade moderna - 0 de que a ciência, por ser antagônica à fé religiosa, substituindo a crença em Deus pela crença no cientista, se basta por uma crença absoluta numa exagerada racionalidade científica. A crítica à ciência moderna persiste e demonstra que a busca de um caminho único como "solução", seja pela fé na ciência, seja pela fé na religião (ou em qualquer outra instituição social), resulta no que é desde o início: frustração.

\section{Notas e referências bibliográficas}

Ariadne Chloe Mary Furnival é doutora em Política Científica e Tecnológica pela Universidade Estadual de Campinas e professora associada do Departamento de Ciência da Informação e Programa de Pós-Graduação em Ciência, Tecnologia e Sociedade da Universidade Federal de São Carlos. E-mail: chloe@ufscar.br.

Marco Donizete Paulino da Silva é mestre e doutor em Ciência, Tecnologia e Sociedade pela Univ. Federal de São Carlos. E-mail: marco_donizete@yahoo.com.br.

1 ASSIS, Machado. 0 alienista. Porto Alegre: L\&PM. 1998.

2 MINAYO, Maria Cecília de S. Hermenêutica-dialética como caminho do pensamento social. In: MINAYO, Maria Cecília de S.; DESLANDES, Suely Ferreira (Orgs). Caminhos do pensamento: epistemologia e método. Rio de Janeiro: Editora Fio Cruz, 2002. p. 83-107.

3 TOUMEY, Christopher P. The moral character of mad scientists: a cultural critique of science.Science, Technology and Human Values, v.17, n.4, p. 411-437. 1992.

4 POE, Edgar Allan. The system of Dr. Tarr and Professor Fether. Classic Reader, 2015. Disponível em: http://www.classicreader.com/read.php/bookid.1394/ sec.1/ Acesso em: 19 jul. 2016.

5 MORAES, Régis de. Evoluções e revoluções da ciência atual. Campinas: Alínea, 2007, p. 84.

Idem.

Idem.

ABREU, Jean Luiz Neves. A Colônia enferma e a saúde dos povos: a medicina das 'luzes' e as informações sobre as enfermidades da América portuguesa. História, Ciências, Saúde - Manguinhos, v.14, n.3, p.761-778, jul.-set. 2007.

$9 \quad$ Idem, p. 766

10 CHAUÍ, Marilena. Convite à filosofia. São Paulo: Editora Ática, 2000, p. 358.

11 ASSIS, op. cit., 1998, p. 10.

12 ANDERY, Maria Amália Pie Abib; SÉRIO, Tereza Maria de Azevedo Pires. Há uma ordem imutável na natureza e o conhecimento a reflete: Auguste Comte (1798-1857). In: ANDERY, Maria Amália Pie Abib et al. Para compreender a ciência: uma perspectiva histórica. Rio de Janeiro: Espaço e Tempo; São Paulo: EDUC, p.373-393. 1996.

13 Idem, p. 376.

14 MINAYO, Maria Cecilia de S.; SANCHES, Odécio. Quantitativo-qualitativo: oposição ou complementaridade? Cadernos de Saúde Pública, v.9, n.3, p.239248. July/Sept., 1993, p. 243.

15 Idem.

16 JAPIASSU, Hilton. Introdução à epistemologia da psicologia. Rio de Janeiro: Imago, 1977, p. 42

17 CUNHA, Maria Clementina Pereira. Ainda o Juquery: notas para um (velho) debate. Lua Nova-Revista de Cultura e Política, São Paulo, v.3, n.4, 1987 , p. 4, 1987.

18 CUNHA, Maria Clementina Pereira. De historiadoras, brasileiras e escandinavas loucuras, folias e relações de gêneros no Brasil (século XIX e início do XX). Tempo, v.3, n.5, p. 2, 1998.

19 ENGEL, Magali Gouveia. Os delírios da razão: médicos, loucos e hospícios. Rio de Janeiro: Editora FIOCRUZ, 2001, p. 47.

$20 \quad$ Idem, p. 55.

21 Idem, p. 143

22 ABREU, op. cit., 2007.

23 CUNHA, op. cit., 1987.

24 ASSIS, op. cit., 1998.

25 ZIMAN, John M. An introduction to science studies:the philosophical and social aspects of science and technology. Cambridge: Cambridge University Press. 1984, p. 174. 
Idem.

BURKE, Peter. Uma história social do conhecimento: de Gutenberg a Diderot. Rio de Janeiro: Jorge Zahar Editor, 2003.

ZIMAN, op. cit., 1984.

MERTON, Robert K. The Normative Structure of Science. In N. Storer (Ed.) The sociology of science: Theoretical and empirical investigations.Chicago: The University of Chicago Press, 1942, p. 267-278.

31 WEINGART, Peter; MUHL, Claudia; PANSEGRAU, Petra. Of power maniacs and unethical geniuses: science and scientists in fiction film. Public Understanding of Science,v.12, p. 279-287, 2003.

32 ASSIS, op. cit., 1998, p. 49

33 ASSIS, op. cit., 1998, p. 50.

34 JAPIASSU, op. cit., 1977, p. 42.

35 CORBANEZI, Elton. 0 terror do positivo: o alienista e o positivismo comteano. Plural, Revista do Programa de Pos-Graduação em Sociologia da USP, v.22.1, p.209-232, 2015, p. 214

36 MENEZES, Tobias Barreto. A psychologia como sciencia de observação. In: MORAES FILHO, M. (Org.). Curso de litteratura brazileira: ou escolha de varios trechos em prosa e verso. Rio de Janeiro: H. Garnier, 1895, p. 128.

37 BEVILAQUA, Clóvis. Trecho de psychologia das plantas. In: MORAES FILHO, M. (Org.). Curso de litteratura brazileira: ou escolha de varios trechos em prosa e verso. Rio de Janeiro: H. Garnier, 1895.

38 ORLANDO, Arthur. 0 evolucionismo e o positivismo. In: MORAES FILHO, M. (Org.). Curso de litteratura brazileira: ou escolha de varios trechos em prosa e verso. Rio de Janeiro: H. Garnier, 1895, p. 132.

39 BASALLA, George. Pop science: the depiction of science in popular culture. In: HOLTON, Gerald; BLANPIED, William A. (eds). Science and its public: the changing relationship. Boston: Springer, p.261-278. 1976.

40 SHELLEY, Mary. Frankenstein or The Modern Prometheus. The Internet Archive, 2013. Disponível em: https://ia801607.us.archive.org/19/items/ Frankenstein1818Edition/frank-a5.pdf . Acesso em: 26 jul. 2016.

41 BASALLA, op. cit., 1976; ROCOUE, Lucia de La; TEIXEIRA, Luiz Antonio. Frankenstein, de Mary Shelley, e Drácula, de Bram Stoker: gênero e ciência na literatura. História, Ciências, Saúde - Manguinhos, v.8, n.1, p. 10-34. 2001; HAYNES, Roslynn. From alchemy to artificial intelligence: stereotypes of the scientist in Western literature. Public Understanding of Science, v.12, p.243-253, 2003

42 HAYNES, op. cit.

43 Idem.

45 Idem, p. 18

46 SHELLEY, op. cit., 2013.

47 WELLS, Herbert George. The Island of Doctor Moreau. A Possibility. New York: Stone \& Kimball, 2012.

48 STEVENSON, Robert Louis. The strange case of Dr. Jekyll and Mr. Hyde. In: The works of Robert Louis Stevenson.London: Eveleigh Nash \& Grayson, [192-?], p.1-104.

49 CHAUVIN, Jean Pierre. Saber, política e navalha: o mandonismo brasileiro em 0 Alienista, de Machado de Assis. XI CONGRESSO INTERNACIONAL DA ABRALIC. 13 a 17 de julho de 2008, USP - São Paulo, Brasil. 2008.

50 CHALHOUB, Sidney. Moro é o alienista de Machado de Assis. Diário do Centro do Mundo, 19 mar., 2016. Disponível em: http://www.diariodocentrodomundo. com.br/moro-e-0-alienista-de-machado-de-assis-por-sidney-chalhoub-de-harvard/. Acesso em: 23 fev. 2017.

51 HUXLEY, Aldous. Brave new world. New York: Harper \& Row Publishers, 1946.

52 BACK, Kurt W. Frankenstein and brave new world: Two cautionary myths on the boundaries of science. History of European Ideas, v.20, n.1-3, p.327-332. 1995

53 ASSIS, op. cit., 1998, p. 66.

54 IRWIN, Alan. Citizen science: a study of people, expertise and sustainable development. London: Routledge, 1995, p. 108.

55 CORBANEZI, op. cit., 2015, p. 229.

$56 \quad$ IRWIN, op. cit., 1995.

57 BYKO, Maureen. Shedding a light on 18th century science: the works of Joseph Wright of Derby. Journal of the Minerals, Metals \& Materials Society, v. 59, n. 6, p. 13-17, 2007, p. 1.

58 Idem

59 ASSIS, op. cit., 1998, p. 30.

$60 \quad$ Idem, p. 36.

61 ALVES, Rubem. Filosofia da ciência: introdução ao jogo e suas regras. São Paulo: Editora Brasiliense. 1981, p. 30

62 ASSIS, op. cit., 1998, p. 59.

63 GLEDSON, John. Machado de Assis: impostura e realismo. São Paulo: Cia. das Letras. 1984, p. 92.

64 Idem, p. 93

65 Idem, p. 142 
66 FLICKER, Eva. Between brains and breasts - women scientists in fiction film: on the marginalization and sexualization of scientific competence. Public Understanding of Science, v.12, p.307-318. 2003.

67 A VIDA de Louis Pasteur. Direção: William Dieterle. United States of America: Warner Brothers. 85 min. 1936.

68 FLICKER, op. cit., 2003.

69 ASSIS, op. cit., 1998, p. 37.

70 CUNHA, op. cit., 1998.

71 Idem, p. 14.

72 HAYNES, op. cit., 2003, p. 247.

[Artigo recebido em Abril de 2017. Aceito para publicação em Julho de 2018] 